\title{
On the Reorganization of Incentive Structure to Promote Delay Tolerance: A Therapeutic Possibility for AD/HD?
}

\author{
Edmund J.S. Sonuga-Barke \\ Developmental Brain-Behavior Unit, University of Southampton, \\ Highfield, Southampton, England SO17 1BJ
}

SUMMARY

This paper brings together two recent insights into attention deficit/hyperactivity disorder (AD/HD) to provide the rationale for a novel approach to treatment. First is the suggestion, backed up by data from randomized trials, that training and practice in carefully selected cognitive activities (executive and attentional training) and tasks can provide a way of modifying the processes underlying cognitive, especially executive, deficits in AD/HD. Second, is the idea that AD/HD is a neuropsychologically heterogeneous disorder resulting from motivational alterations, specifically an increased intolerance for delay, as well as executive deficits. The paper builds on these two insights to explore the possibility that the motivational alterations underpinning delay aversion can be modified through specific training regimes in a way equivalent to that found with executive and attentional training. The requirements for such an approach are set out. Delay fading is proposed as a possible basis for reorganizing delay experience, altering the incentive value of delay (e.g., increasing tolerance for delay), thereby reducing $\mathrm{AD} / \mathrm{HD}$ symptoms.

Reprint requests to: E.J.S. Sonuga-Barke, Developmental Brain-Behavior Unit, University of Southampton, Highfield, Southampton, England SO17 1BJ e-mail: eb3@soton.ac.uk

\section{INTRODUCTION}

To understand possible targets for individual neuropsychological training in attention deficit hyperactivity disorder ( $\mathrm{AD} / \mathrm{HD}$ ), we need to conduct an analysis of the psychological basis of the disorder. Traditionally, $\mathrm{AD} / \mathrm{HD}$ is regarded as a disorder of dysregulation. Brain-behavior relations are viewed as fully mediated by neuropsychological deficits in executive functions-higher-order, topdown, cognitive processes allowing the appropriate set maintenance and shift that facilitate the flexible pursuit of future goals (Barnett et al., 2001; Bayliss \& Roodenrys, 2000; Cornoldi et al., 1999; Karatekin \& Asarnow, 1998; Pennington \& Ozonoff, 1996; Seidman et al., 1997; Sergeant et al., 2002;. Clark et al., 2000).

At a neurobiological level, executive functions appear to be underpinned by one of a number of functionally segregated but neuroanatomically proximate anterior brain circuits connecting cortical foci, basal ganglia, and thalamic nuclei (Nakano et al., 2000; Robbins et al., 1995; Tekin \& Cummings, 2002). This circuit (the executive circuit) links the pre-frontal cortex to the dorsal neo-striatum (preferentially the caudate nucleus) with reciprocal excitatory connections back up to cortical regions via the dorso-medial sections of the thalamus. Dopamine, widely implicated in $\mathrm{AD} / \mathrm{HD}$, is a key neuromodulator of this circuit (Russell, 2002; Williams et al., 2002; Robbins \& Everitt, 1992; Solanto, 2002). 
Motivationally based models, which shift the focus from executive functions to suboptimal reward processes, offer an alternative basis for AD/HD (Sagvolden, 1991; Sagvolden et al., 1998; Sonuga-Barke, 1994). For instance, $\mathrm{AD} / \mathrm{HD}$ can be seen as delay aversion that develops out of a higher rather than normal level of delayed-reward discounting and is manifest in the attempts to escape or avoid delay (Sonuga-Barke et al., 1992). Evidence exists linking $\mathrm{AD} / \mathrm{HD}$ with a hypersensitivity to delay and consequent difficulties in both waiting for desired outcomes and working effectively over extended periods (Kuntsi et al., 2001; Sonuga-Barke et al., 1994; Schweitzer \& Sulzer-Asaroff, 1995; Tripp \& Alsop, 2001). This difficulty in waiting appears to be independent of the inhibitory deficits associated with executive dysfunction (Neef et al., 2001; Solanto et al., 2001). A double dissociation between inhibitory deficits and waiting for valued outcomes is confirmed by the observation that children with $\mathrm{AD} / \mathrm{HD}$ can wait, even when the waiting involves inhibition, but they often choose not to wait, even when the waiting does not involve inhibition (Sonuga-Barke et al., 1994). Interestingly, the neurobiology of delay aversion and inhibitory deficits can share some common elements. It is likely that delay aversion is also related to alterations in one of the cortio-basal-ganglia circuits modulated by dopamine, this time, linking the ventral striatum (in particular the nucleus accumbens) to frontal regions (especially the anterior cingulate and orbito-frontal cortex), reciprocated via the ventral pallidum and related structures through the thalamus (Robbins \& Everitt, 1996).

In keeping with the idea that $A D / H D$ is the result of a single core deficit, executive dysfunction, and delay aversion models have been regarded as competing rather than complementary. In opposition to this view, we have argued for a dual pathway hypothesis of $\mathrm{AD} / \mathrm{HD}$, in which alterations within the executive circuit and the reward circuit constitute more-or-less discrete neuropsychological bases for dissociable psychological processes leading to executive/inhibitory deficits and delay aversion, respectively (Sonuga-Barke, 2002; 2003). Although initial results are suggestive of the existence of independent delay-aversion and executive processes in $\mathrm{AD} / \mathrm{HD}$, further study of the relation between these processes is required to test this hypothesis properly. A recent head-tohead study (Solanto et al., 2001) of delay aversion and inhibitory deficits in $\mathrm{AD} / \mathrm{HD}$ supports this view by showing that delay aversion and executive deficits are independent of each other but equally strongly associated with $\mathrm{AD} / \mathrm{HD}$.

\section{DELAY AVERSION AS AN ALTERNATIVE TO EXECUTIVE DYSFUNCTION AS A NEUROPSYCHOLOGICAL TREATMENT TRAINING TARGET FOR AD/HD.}

The current treatment options for $A D / H D$, both pharmacological and non-pharmacological, are limited in the extent to which they show maintained and generalized efficacy. In both cases, intervention appears to offer short-term and context-dependent symptomatic relief. Medication is effective only while the child is medicated. Behavior management is likely to be effective only in changing a child's behavior while the special contingencies are maintained. Its effects on parental coping are necessarily relevant only to the home setting. The failure of the effects of interventions to generalize is therefore a major issue of concern.

Neuropsychological remediation (e.g., executive training) is an alternative approach to intervention that may offer the possibility of a $\mathrm{m}$ ore fundamental and long-lasting improvement. This model was first applied with considerable success to stroke or brain injury patients (Park et al., 1999). The aim is to exercise and strengthen the neuroanatomical circuits that are thought to be 
deficient in a particular condition and so to bring about generalized and long lasting improvement in cognitive functioning and behavioral control. Recently this approach has been successfully applied to children with $\mathrm{AD} / \mathrm{HD}$ in a number of small-scale studies (Kerns et al., 1999; Klingberg et al., 2002). In contrast to both medical management and parent training, neuropsychological approaches are directly informed by current models of the psycho-patho-physiology of $\mathrm{AD} / \mathrm{HD}$. In this sense, such approaches are theoreticallyinformed. Furthermore, they offer the opportunity to tailor particular treatments to specific deficits. In principle, neuropsychological approaches offer the chance to alter fundamental aspects of the condition and so may have the potential to produce sustained and generalizable treatment effects.

In keeping with the dominant model of $\mathrm{AD} / \mathrm{HD}$, to date most attempts to address the underlying neuropsychological impairments through training have focused on the executive dysfunction pathway. This pa thway is a good starting point given the evidence linking $\mathrm{AD} / \mathrm{HD}$ to deficits in response inhibition, working memory, planning, and set shift. Nevertheless, the evidence supporting delayed reward discounting and delay aversion as a significant cause of $\mathrm{AD} / \mathrm{HD}$, and perhaps a distinct pathway, suggests that supplementing existing neuropsychological training programs with modules aimed at reducing reward discounting and delay aversion would increase the scope and effectiveness of the neuropsychogical training approach. Indeed, although standard attention training may be of considerable value to those $\mathrm{AD} / \mathrm{HD}$ children whose primary problem is in the area of executive control, such training might do little for those children with a more motivationally based neuropsychological variant.

Executive/attention training and delay restructuring are based on the same general principle; both aim to target basic neuropsychological processes and networks. This approach is based on the view that neuro-adaptation within these networks will promote long term and generalizable improvement. There are, however, likely to be different conceptual emphases in formulations relating to these two approaches to treatment. Delay Aversion is not a deficit to be corrected but rather a motivational style. The aim of the restructuring will be to alter fundamentally the child's preference structure by either increasing the efficiency with which the system codes and responds to delayed rewards or the incentive value of reward delay relative to other reward parameters (size, quality etc). Whereas the aim of classical attention training is to 'strengthen' deficient neuro-anatomical networks in delay training, the focus is probably best placed on modifying the underlying reward preference hierarchies by changing the nature of activity of the neurotransmitters involved in reward-related activity. Much discussion in the literature has focused on the neurotransmitter dopamine in the pathophysiology of $\mathrm{AD} / \mathrm{HD}$; the so called dopamine deficit hypothesis (Solanto, 1998).

\section{TWO COMPONENTS REQUIRED FOR DELAY RESTRUCTURING: DELAY DESENSITIZATION AND STIMULUS-TO- DELAYED-REWARD COUPLING}

Dopamine can fire in either tonic or phasic modes and these modes appear to have specific roles in the response to rewarding and punishing stimuli (Shultz, 1998; Shultz, 2002; Wightman \& Robinson, 2002). The burst-like phasic mode appears to be linked to the presentation of unexpected rewards or to stimuli that predict the later delivery of expected rewards. The slower changes in the dopamine tone appear to be related to the incentive value of rewards or punishments.

One can see two distinct stages in the emergence of delay aversion in children with $\mathrm{AD} / \mathrm{HD}$, and each can be conceptualized as related to one aspect of the proposed dopamine deficit in 
$\mathrm{AD} / \mathrm{HD}$. First, $\mathrm{AD} / \mathrm{HD}$ children have a biologically based steeper delayed-reward discount function that may be related to a weaker tonic response to expected reward. Under normal circumstances, the UCS would elicit a short acting phasic dopamine burst that would signal the future delivery of the larger reward. Because children with $\mathrm{AD} / \mathrm{HD}$ have a steeper delayed reinforcement gradient this dopamine signaling system may be weakened in the $A D / H D$ child and the ability of the dopamine system to signal future rewards compromised. This account suggests that training that aims to strengthen the CS-UCS link can correct this problem-we might call this signal to delayedreward coupling.

The second stage of the emergence of delay aversion involves the negative emotional response that emerges as the inability to wait for signaled reward (linked to the steeper delayed reward gradient) leads to the development of a generalized negative emotional response to delay-related cues, tasks, and situations. This response can be related to dopamine tone, which appears to increase in response to the experience of motivationally significant stimuli whether positive or negative (although the time course may vary as a function of valence). The presentation of delay (and cues that predict delay) can lead to changes in dopamine tone associated with aversive events that motivates the escape or avoidance of that delay. Training that allows repeated exposure to rewarded delay could lead to the habituation of the dopamine signal associated with aversive events, in this case delay, and so reduce delay avoidant behavior. This in turn changes the child's preference structure, increasing the incentive value of reward size and reward density relative to delay. It is of course possible that these tonic and phasic processes interact with low phasic bursting to CS for rewards compounding the effects of the tonic response to aversive stimuli. Increasing the phasic signal and reducing the tone will have the added benefit of increasing the phasic signal-to-noise ratio and increase the power of predictors of delayed reward to control responding.

\section{DELAY RESTRUCTURING; A SUCCESSFUL IMPLEMENTATION USING A FADING PROCEDURE}

Taken together these two processes suggest that the repeated presentation of predictable and rewarded delay of gradually increasing size, so called delay fading, may provide the most effective basis for altering delay aversion and hyper-discounting of delayed reward found in $\mathrm{AD} / \mathrm{HD}$. This is supported by a recent study by Neef and colleagues (2001) who demonstrated that such a change in the structure of incentives could be achieved with $\mathrm{AD} / \mathrm{HD}$ children. In this study, a fading procedure was used to increase preference for delayed over immediate rewards given for completion of math problems. In an initial assessment phase, the relative value of reward delay, reward quality, reward density, and task effort were assessed by giving children choices between combinations of these choice qualities. For example, low quality rewards available immediately after the session were set against high quality rewards available only at the start of the next session (24 hours later). All three $\mathrm{AD} / \mathrm{HD}$ children valued reward immediacy over high quality, high-density rewards or low effort tasks.

In the training phase, the two most potent dimensions identified in the assessment phase were set against each other. The baseline assessment involved a replication of the assessment phase with immediate reward being compared with a 24 hour delay before reward delivery. All children preferred the immediate reward. At the start of training only a 15 second delay to the higher quality reward was introduced. When a child had established a preference for the delayed alternative (e.g., $70 \%$ or more of their time allocated to this task) to the problem set associated 
with this reward, the delay was increased to 30 minutes. This fading of delay increased until it reached 24 hours. This fading procedure was successful with preference for the delayed alternative increasing to nearly $100 \%$ post assessment. Although the study had a number of limitations (no RCT design, etc.), it does provide the first evidence that faded increases in delay levels in the context of competing reward dimensions, identified through a brief preassessment, can alter the incentive structure of children with $\mathrm{AD} / \mathrm{HD}$.

Importantly, these results can be understood using the tonic and phasic dopamine hypotheses. First, training may have strengthened the CS-UCS link through repeated presentations of certain delayed outcomes. Second, it may have provided controlled exposure to delays of increasing length that desensitized the child to the aversive properties of the delay. It is interesting that increase in 'self control' was not the result of the promotion of 'self talk' or other 'cognitive' techniques. One cannot, however, rule out the possibility that these children spontaneously developed more effective 'self talk' as a consequence of training.

\section{CONCLUSIONS}

In the present chapter, we present a rationale for the introduction of delay restructuring as an element in the treatment of AD/HD by neuropsychological training. At the heart of this approach is the operant technique of delay fading, in which children are presented with repeated exposure to rewarded predictable delay periods of gradually increasing length. We argue that this type of treatment should be successful for two reasons. First, because it provides the basis for an effective coupling of signals for delay reward and the reward themselves, so increasing the power by which signals of delayed reward control behavior. Second, because it desensitizes the child to the aversive properties of delay through repeated exposure.

\section{REFERENCES}

Barnett R, Maruff P, Vance A, Luk ESL, Costin J, Wood C, Pantelis C. 2001. Abnormal executive function in attention deficit hyperactivity disorder: the effect of stimulant medication and age on spatial working memory. Psychol Med 31: 11071115.

Bayliss DM, Roodenrys S. 2000. Executive processing and attention deficit hyperactivity disorder: an application of the supervisory attentional system. Dev Neuropsychol 17: 161-80.

Clark C, Prior M, Kinsella GJ. 2000. Do executive function deficits differentiate between adolescents with $\mathrm{AD} / \mathrm{HD}$ and Oppositional Defiant/Conduct Disorder? A neuropsychological study using the Six Elements Test and Hayling Sentence Completion Test. J Abnormal Child Psychol 28: 403-414.

Cornoldi C, Barbieri A, Gaiani C, Zocchi S. 1999. Strategic memory deficits in attention deficit disorder with hyperactivity participants: The role of executive processes. Dev Neuropsychol 15: 53-71.

Karatekin C, Asarnow, RF. 1998. Working memory in childhood onset schizophrenia and attention deficit/hyperactivity disorder. Psychiat Res 80: 165-176.

Kerns KA, Eso K, Thomson J. 1999. Investigation of a direct intervention for improving attention in young children with ADHD. Devel Neuropsychol 16: 273-295.

Klingberg T, Forssberg H, Westerberg H. 2002. Training of working memory in children with ADHD. J Clin Exper Neuropsychol 24: 781-791.

Kuntsi J, Oosterlaan J, Stevenson J. 2001. Psychological mechanisms in hyperactivity: I. Response inhibition deficit, working memory impairment, delay aversion, or something else? J Child Psychol Psychiat 42: 199-210.

Nakano K, Kayahara T, Tsutsumi T, Ushiro $H$. Neural circuits and functional organization of the striatum. J Neurol 2000. 247: 1-15.

Neef NA, Bicard DF, Endo S. 2001. Assessment of impulsivity and the development of self-control in students with attention deficit hyperactivity 
disorder. J Applied Behav Anal 34: 397-408.

Park NW, Proulx GB, Towers WM. 1999. Evaluation of the attention process training programme. Neuropsychological Rehab 9: 135-154.

Pennington BF, Ozonoff S. 1996. Executive functions and developmental psychopathology. J Child Psychol Psychiat 37: 51-87.

Robbins TW, Everitt BJ. 1996. Neurobehavioral mechanisms of reward and motivation. Curr Opin Neurobiol 6: 228-36.

Robbins TW, Everitt BJ. 1992. Functions of dopamine in the dorsal and ventral striatum. Semin Neurosci 4: 119-28.

Robbins TW, Shallice T, Burgess PW, James M, Rogers RD, Warburton E, Wise RSJ. 1995. Selective impairments in self-ordered working memory in a patient with a unilateral striatal lesion. Neurocase 1: 217-230.

Russell, VA. 2002. Hypodopaminergic and hypernoradrenergic activity in prefrontal cortex slices of an animal model for attention-deficit hyperactivity disorder-the spontaneously hypertensive rat. Behav Brain Res 130: 191-196.

Sagvolden T. 1991. The attention deficit disorder might be a reinforcement deficit disorder. In: Georgas J, Manthouli M, Besevegis E, Kokkevi A, eds. Contemporary Psychology in Europe: Theory, Research and Application. Gottengin, Germany: Hogrefe and Huber; 131-43.

Sagvolden T, Aase H, Zeiner P, Berger D. 1998. Altered reinforcement mechanisms in attentiondeficit/hyperactivity disorder. Behav Brain Res 94: 61-71.

Schweitzer JB, Sulzer-Azaroff B. 1995. Self-control in boys with attention deficit hyperactivity disorder: Effects of added stimulation and time. $\mathrm{J}$ Child Psychol Psychiat 36: 671-686.

Schultz W. 1998. Predictive reward signal of dopamine neurons. J Neurophysiol 80: 1-27.

Schultz W. 2002. Getting formal with dopamine and reward. Neuron 36: 241-263.
Seidman LJ, Beiderman J, Faraone SV, Wever W, Ouellette C. 1997. Toward defining a neuropsychology of attention deficit-hyperactivity disorder: Performance of children and adolescents from a large clinically referred sample. J Consult Clin Psychol 65: 150-160.

Sergeant JA, Geurts H, Oosterlaan J. 2002. How specific is a deficit of executive functioning for attention deficit/hyperactivity disorder? Behav Brain Res 130: 3-28.

Solanto MV. 2002. Dopamine dysfunction in $\mathrm{AD} / \mathrm{HD}$ : integrating clinical and basic neuroscience research, Behav Brain Res 130: 65-71.

Solanto MV, Abikoff H, Sonuga-Barke E, Schachar R, Logan GD, Wigal T, et al. 2001. The ecological validity of delay aversion and response inhibition as measures of impulsivity in $\mathrm{AD} / \mathrm{HD}$ a supplement to the NIMH multi-modal treatment study of AD/HD. J Abnorm Child Psychol 29: 215-28.

Sonuga-Barke EJS. 1994. On dysfunction and function in psychological accounts of childhood disorder. J Child Psychol Psychiat 35: 801-815.

Sonuga-Barke EJS, Williams E, Hall M, Saxton T. 1996. Hyperactivity and Delay Aversion III. The effect on cognitive style of imposing delay after errors. J Child Psychol Psychiat 37: 189-194.

Tekin S, Cummings JL. 2002. Frontal-subcortical neuronal circuits and clinical neuropsychiatryAn update. J Psychosom Res 53: 647-654.

Tripp G, Alsop B. 2001. Sensitivity to reward delay in children with attention deficit hyperactivity disorder (AD/HD). J Child Psychol Psychiat 42: 691-698.

Wightman RM, Robinson DL. 2002. Transient changes in mesolimbic dopamine and their association with 'reward'. J Neurochem 82: 721-735.

Williams D, Tijssen M, van Bruggen G, Bosch A, Insola A, Di Lazzaro V, et al. 2002. Dopaminedependent changes in the functional connectivity between basal ganglia and cerebral cortex in humans. Brain 125: 1558-1569. 

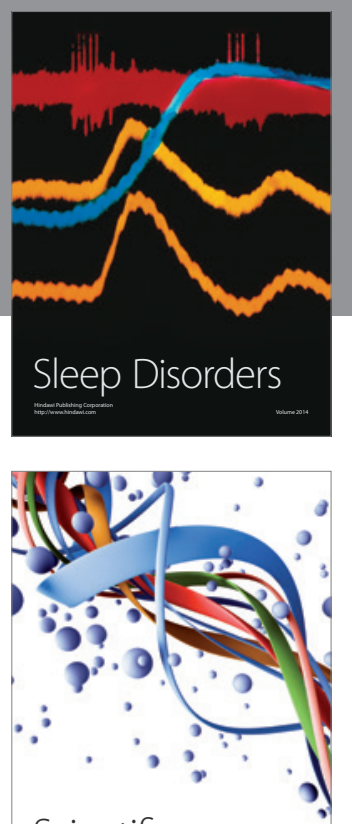

Scientifica
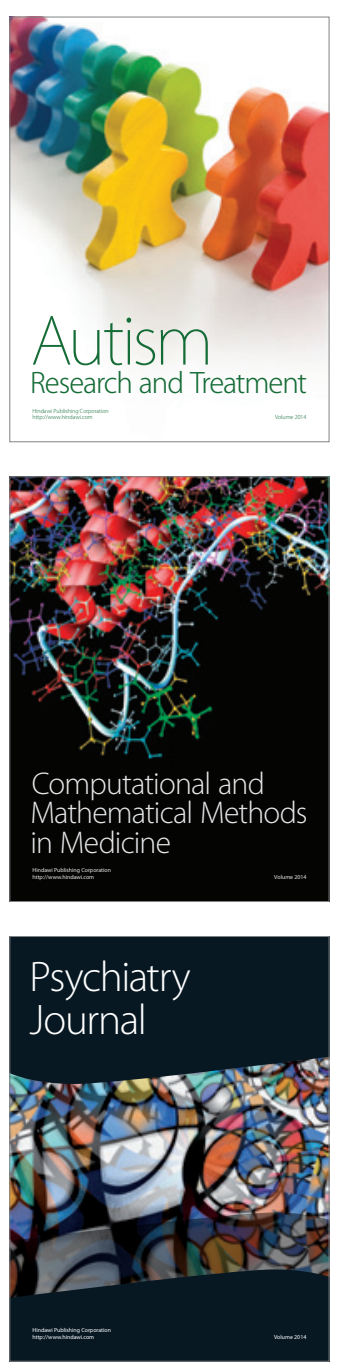
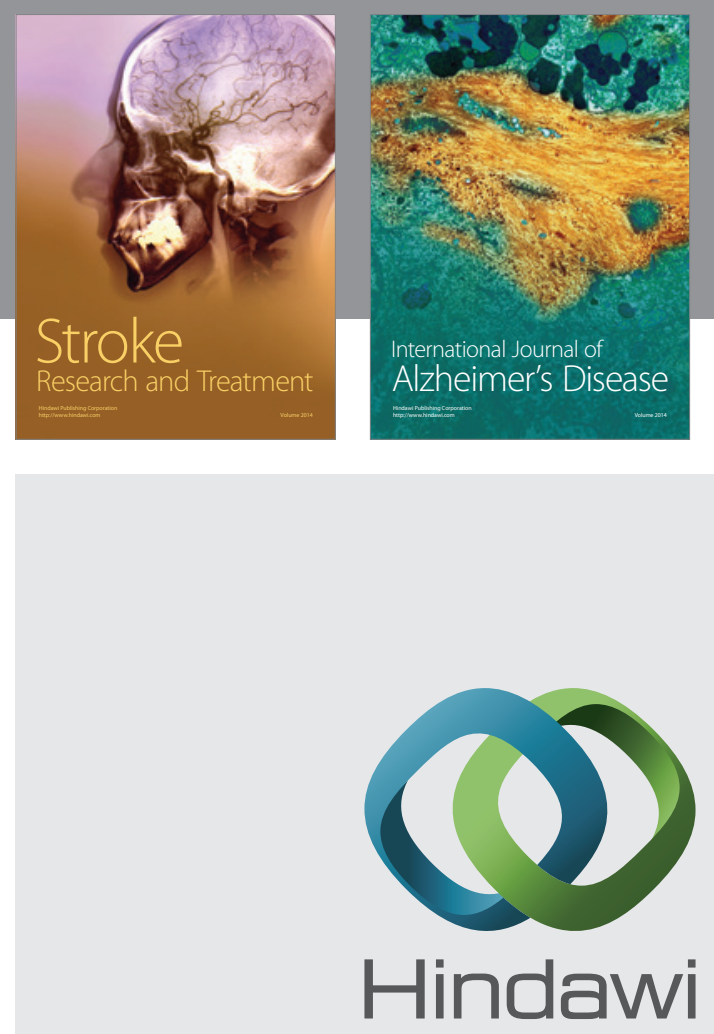

Submit your manuscripts at

http://www.hindawi.com
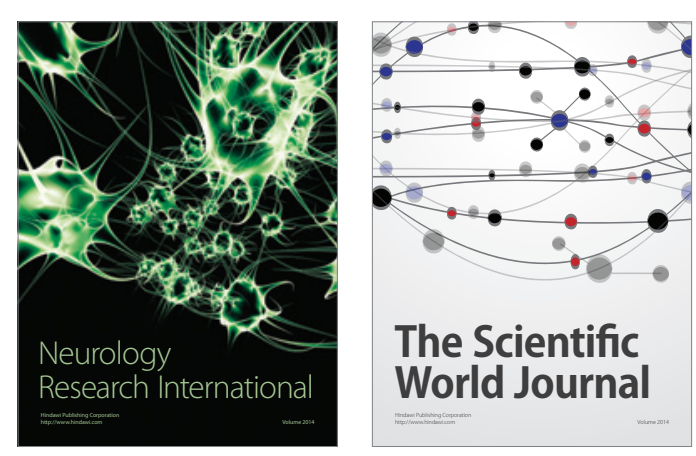

The Scientific World Journal

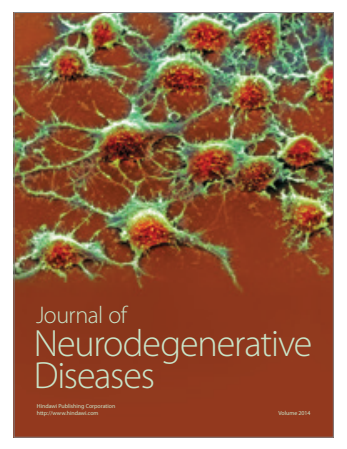

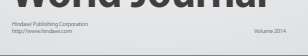

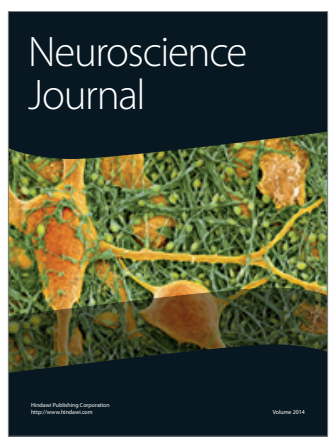

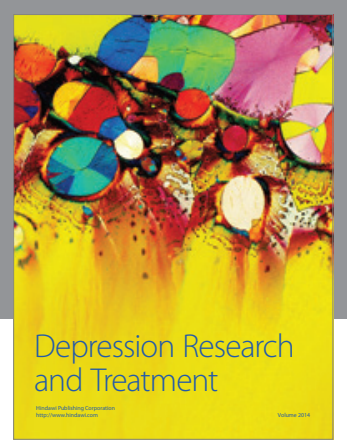
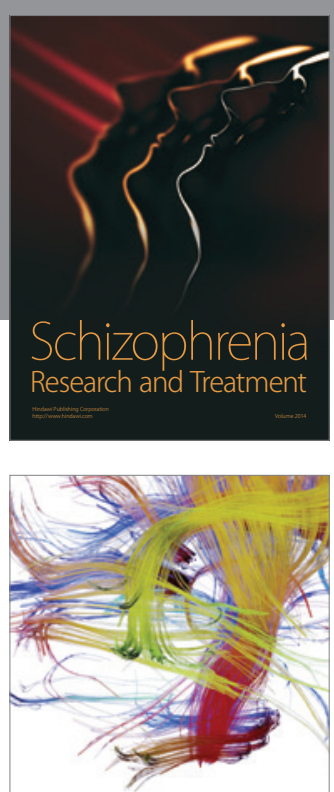

Brain Science

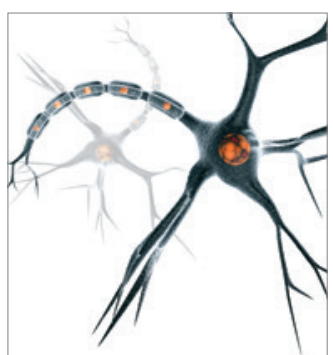

Neural Plasticity
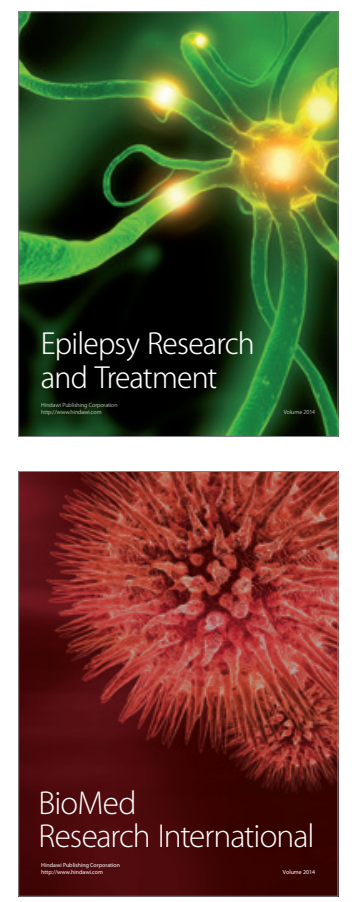

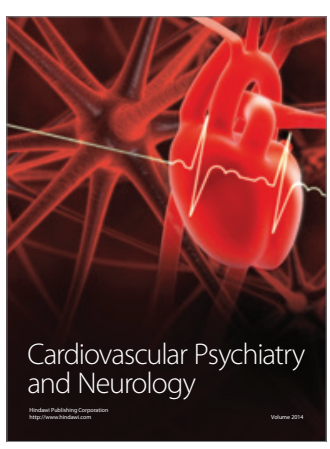

Parkinson's

Disease
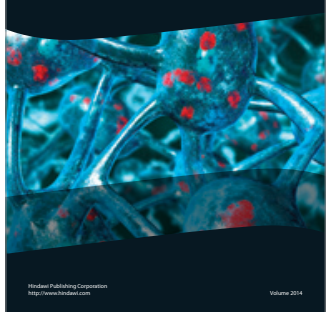